\title{
IDENTIFICAÇÃO E DESCRIÇÃO DE CLASSES ETNOPEDOLÓGICAS DE TERRAS E ATRIBUTOS COM AGRICULTORES FAMILIARES DE ANTONINA E MORRETES - PR
}

\author{
Andressa Kerecz Tavares ${ }^{1}$ \\ Marcelo Ricardo de Lima ${ }^{2}$ \\ Carlos Augusto dos Santos Faias Júnior ${ }^{3}$ \\ Manoel Flores Lesama ${ }^{4}$
}

\section{RESUMO}

Este trabalho teve como objetivo identificar e descrever os conhecimentos etnopedológicos relacionados à classificação de terras agrícolas com agricultores familiares dos municípios de Antonina e Morretes - PR. A seleção do grupo informante ocorreu conforme a disponibilidade dos indivíduos em participar da pesquisa, sendo entrevistados 20 agricultores familiares, juntamente com seu grupo familiar. O conhecimento etnopedológico dos agricultores foi identificado e descrito através de diagnóstico participativo que consistiu em quatro etapas: 1) entrevistas narrativas; 2) elaboração de mapas participativos; 3) caminhadas na propriedade rural; 4) reunião geral. Os resultados mostraram que os agricultores reconhecem e classificam os diferentes tipos de terras existentes nas unidades de exploração agrícola locais, sendo identificadas e descritas quatro classes: 1) "Terra de Morro", 2) "Sabão de Caboclo", 3) "Terra Argilosa" e 4) "Terra de Desmonte". Os atributos empregados para a classificação das terras mencionadas seguiram a sequência: posição na paisagem, textura, cor, drenagem, fertilidade e conteúdo de matéria orgânica. O sistema de classificação dos agricultores entrevistados possibilita identificar e descrever de forma objetiva as terras, utilizando atributos e relacionando-os com aspectos cognoscíveis, como aptidão agrícola e manejo do solo.

Palavras-chave: agricultura familiar, classificação de terras, conhecimento local, etnoconhecimento ou etnociência.

\footnotetext{
${ }^{1}$ Graduada em Engenharia Agronômica. Especialista em Educação do Campo. Mestre em Ciência do Solo. Professora Assistente do Curso de Licenciatura em Educação do Campo - Ciências da Natureza da Universidade Federal do Paraná - Setor Litoral (UFPR). E-mail: andressa.tavares@ufpr.br

${ }^{2}$ Graduado em Engenharia Agronômica. Especialista em Educação á Distância. Mestre em Ciência do Solo. Doutor em Produção Vegetal. Professor Associado do Departamento de Solos da Universidade Federal do Paraná (UFPR). E-mail: mrlima@ufpr.br

${ }^{3}$ Graduado em Engenharia Agronômica. Especialista em Gestão Ambiental e Desenvolvimento Sustentável. Técnico administrativo em Educação da Universidade Federal do Paraná - Setor Litoral (UFPR). E-mail: carlos.faias@ufpr.br

${ }^{4}$ Graduado em Engenharia Agronômica. Mestre em Zootecnia Rural. Doutor em Produção Vegetal. PósDoutorado. E-mail: manoel.lesama@ufpr.br
} 


\title{
IDENTIFICATION AND DESCRIPTION OF ETHNOPEDOLOGICAL CLASSES AND ATTRIBUTES WITH FAMILY FARMERS OF ANTONINA AND MORRETES - PR
}

\begin{abstract}
This study aimed to identify and describe the knowledge related to the classification and attributes used by farmers in the cities of Antonina and Morretes - PR. The informant group selection occurred as the availability of individuals to participation the research. A total of 20 farmers were interviewed along with their family. The ethnopedological knowledge of farmers was identified and described through participatory diagnosis which consisted of four steps:1) narrative interviews, 2) participatory mapping, 3) walking around the farm, 4) general meeting. The results show that farmers recognize and classify the different existing types of existing lands in the units of local farm, being identified and described four classes of land:1) "Terra de Morro", 2)“Sabão de Caboclo", 3)“Terra Argilosa" and 4)"Terra de Desmonte". The mentioned attributes used for classification of lands have followed the sequence of importance, landscape position, texture, color, drainage, fertility and organic matter. The classification system of farmers can identify and describe objectively the lands, using attributes and relating them to observable aspects such as land suitability and soil management.
\end{abstract}

Keywords: family farming, land classification, local knowledge, ethnoknowledge and ethnoscience.

\section{INTRODUÇÃO}

O solo é um dos principais alicerces para a sobrevivência da vida no planeta. No desenvolvimento das sociedades teve fundamental importância e a partir do domínio da agricultura, os seres humanos criaram técnicas para o manejo e irrigação, domesticaram animais para auxiliar no plantio e na colheita, deixaram de ser nômades e instalaram-se sobre terras ${ }^{5}$ férteis que posteriormente originaram vilarejos, os quais foram os embriões para futuras sociedades mais estruturadas e complexas (MAZOYER; ROUDART, 2010).

Verifica-se que través da experiência adquirida na agricultura e nos demais uso e manejo do solo, diversos povos criaram formas de classificar suas terras. Os primeiros relatos de categorização foram descritos há aproximadamente 7000 anos a.C. na Palestina, 2200 anos a.C. na China e 350 anos a.C. na Grécia (BOULAINE, 1989). Também foram descritas classificações no antigo Egito, Império Romano e na África (KRASILNIKOV; TABOR, 2003; WINIWARTER, 2006). No continente americano, pode-se destacar a civilização Asteca com um modelo complexo de classificação (WILLIAMS; 2006).

\footnotetext{
${ }^{5}$ Terra é o meio ambiente total (natural e cultural) dentro do qual a produção tem lugar, sendo um termo mais amplo que solo. Em adição a solo, seus atributos incluem outras condições físicas, tais como, depósitos minerais, clima e suprimento de água; localização em relação aos centros de comércio, populações e outras terras (CURI et al., 1993).
} 
A ciência do solo moderna surgiu, em 1877, a partir dos estudos de Vasily Vasil'evich Dokuchaev, que se baseou no conhecimento local ${ }^{6}$ dos povos eslavos, utilizando a etimologia russa de alguns nomes que são adotados até hoje nos sistemas de classificação. Como exemplo dessas classes, verifica-se: Chernozem, Solods, Solonetz e Gleisols (KRASILNIKOV; TABOR, 2003). É notável que a pedologia congregou contribuições dos conhecimentos locais de diferentes povos. Entretanto, o desenvolvimento e a modernização da ciência promoveu um distanciamento do diálogo entre cientistas e agricultores, artesãos ou pessoas conectadas ao solo.

Em contrapartida, esse paradigma vem sendo modificado, por estudos que consideram e reconhecem os conhecimentos locais como, por exemplo, a etnoecologia, e dentro dessa abordagem encontra-se a etnopedologia com o objetivo de estudar a interconexão entre solos, a espécie humana e os outros componentes dos ecossistemas (ALVES; MARQUES, 2005). Um dos objetivos da etnopedologia é identificar a classificação local de solos e terras Barrera-Bassols; Zinck (2000), as quais são importantes para conservação dos relatos históricoculturais Siderius; Bakker (2003) e também podem facilitar o diálogo, criando uma linguagem comum entre cientistas, extensionistas e agentes de desenvolvimento (HABARUREMA; STEINER, 1997; BARRIOS et al., 2006; et al.,).

Diversas pesquisas etnopedológicas realizadas no mundo demonstraram a importância das classificações locais como fator determinante no uso, manejo e para uma gestão sustentável das terras, como exemplos podem-se mencionar as pesquisas de Alves; Marques (2005) em um estudo com agricultores artesãos do Agreste paraibano que verificou que as classes de solos distinguidas são destinadas para cultivos e outras para confecção de louças de barro, assim também Benassi et al. (2009) verificou que os agricultores faxinalenses paranaenses possuem um sistema de classificação com níveis hierárquicos detalhados baseados no uso do solo, similarmente Palácio; Arriaga (2005) em uma pesquisa com agricultores mexicanos encontraram um sistema de classes de terras baseado nas finalidade utilitárias do solo. Siderius; Bakker (2003) demonstraram que agricultores holandeses classificam suas terras conforme o relevo e a textura do solo e essas informações são decisivas para o planejamento nas unidades de produção. Strachulski; Floriani (2014) verificaram que os sistemas agrários da região do Paraná tradicional obtêm características especificas conforme os conhecimentos que os agricultores possuem sobre o meio físico, como o solo, e suas relações com a paisagem.

Neste contexto se compreende que o litoral paranaense apresenta-se como uma região relevante para a constituição de conhecimentos etnopedológicos, pois permaneceu isolada geograficamente por mais de 300 anos, devido a presença da Serra do Mar e pela carência de estradas de acesso, as comunidades que ali permaneceram sobreviveram da agricultura e da pesca (MUSSOLINI, 1980). Sendo assim, este trabalho procura fazer uma sistematização dos conhecimentos etnopedológicos referentes á classificação de terras agrícolas e seus atributos com agricultores familiares dos municípios de Antonina e Morretes localizados no litoral paranaense.

\footnotetext{
${ }^{6}$ O conhecimento local fundamenta-se na experiência transmitida entre gerações, e pode sofrer alterações, adaptações e assimilar novas ideias; sendo especifico para o local e pode variar entre os indivíduos de diferentes grupos sociais (SILLITOE, 1998; OUDWATER; MARTIN, 2003).
} 


\section{MATERIAL E MÉTODOS}

A pesquisa foi realizada nos municípios de Antonina e Morretes, localizados no litoral do estado do Paraná (Figura 1), cujas sedes estão nas coordenadas 25

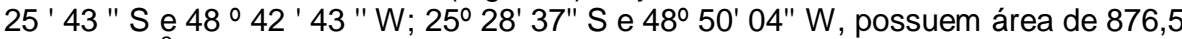
e $687,5 \mathrm{~km}^{2}$ e população censitária de 18.891 e 15.718 habitantes, respectivamente. (IPARDES, 2012).

Figura 1 - Localização dos municípios de Antonina e Morretes e das unidades de produção visitadas.

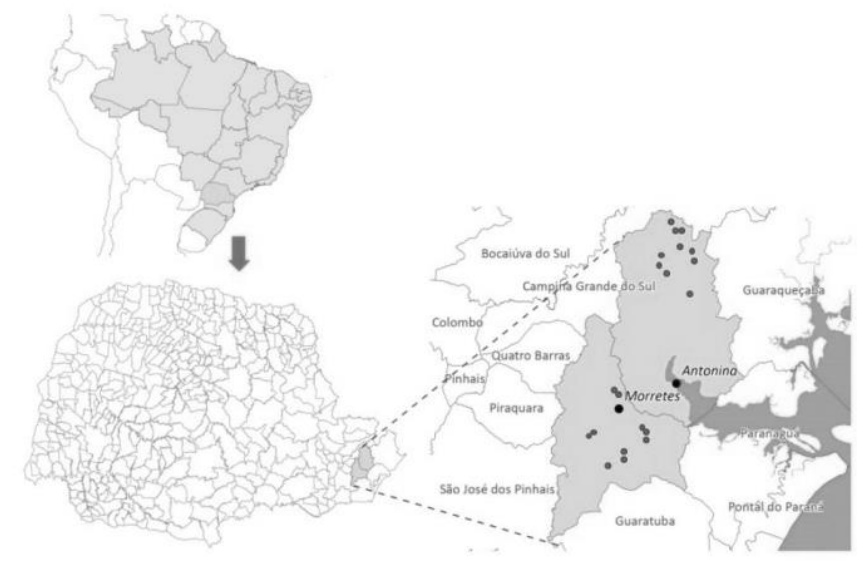

Fonte: (IPARDES, 2012).

Estes municípios possuem porções do relevo íngreme da Serra do Mar, recoberta por extensas áreas remanescentes do bioma Mata Atlântica, sendo a vegetação predominante Floresta Ombrófila Densa (IBGE, 2012).

A planície litorânea é constituída por depósitos marinhos, continentais e mistos e por morros isolados. Nos pequenos gradientes altimétricos, a planície se apresenta como uma paisagem muito heterogênea, onde se desenvolvem os Espodossolos Humilúvicos, em sedimentos eólico-marinhos; os Gleissolos, em sedimentos continentais; e os Organossolos, todos embutidos em cotas geralmente inferiores a 50m. Em altimetrias superiores, em cadeias de elevação ou em morros e morrotes isolados, com cotas de até $240 \mathrm{~m}$ acima do nível do mar, podem ser encontrados Latossolos (com pequena expressão), Argissolos e Cambissolos derivados dominantemente de rochas metamórficas - migmatitos, gnaisses ou xistos (BHERING; SANTOS, 2008).

Nos municípios de Antonina e Morretes são registrados 338 e 686 estabelecimentos agropecuários, com área total de 20.743 ha e 14.377 ha, respectivamente. Deve-se ressaltar que expressiva parte desses municípios é ocupada com unidades de conservação. As propriedades agrícolas desses municípios possuem área média de 66 ha em Antonina e 25 ha em Morretes, e as principais atividades agropecuárias são os cultivos de banana, maracujá, palmito, 
tangerina, arroz, cana-de-açúcar, feijão, mandioca, milho, tomate e pequena criação de animais, como galinhas e bovinos (IPARDES, 2012).

O critério de escolha, o número e as características dos entrevistados se baseou na metodologia de Geilfus (2002), segundo o autor para a formação dos grupos de trabalho é necessário escolher as pessoas da comunidade com interesses comuns e que sejam voluntárias, é recomendado trabalhar em grupos pequenos, pois elevado número de participantes não permite tratar o tema com profundidade devido heterogeneidade de opiniões. No presente trabalho as famílias entrevistadas de Antonina foram apresentadas pela coordenação do projeto de extensão universitária da UFPR Litoral "Feiras: sabores, memórias e identidades das comunidades de agricultores familiares do litoral paranaense". As famílias de Morretes foram apresentadas pelos técnicos do escritório local do Instituto Paranaense de Assistência Técnica e Extensão Rural (EMATER - PR). Foram realizadas entrevistas com 20 famílias de agricultores (10 em cada município), totalizando o número de 103 pessoas. As origens dessas famílias são: nativas, totalmente imigrantes e mistas. Todas as unidades de produção são familiares e destas 18 utilizam o modelo de agricultura convencional e 02 orgânicas, os principais cultivos são maracujá, mandioca, chuchu, gengibre, olerícolas, banana, palmitos entre outras.

O método de análise utilizado na pesquisa é o abdutivo, o qual se destaca pela interpretação e experiência de mundo social por seus membros. Assim, a tarefa do pesquisador é descobrir e descrever essa visão "de dentro" sem impor uma visão "de fora" (BLAIKIE, 2002).

As informações etnopedológicas foram coletadas através da metodologia de Geilfus (2002), de diagnóstico participativo, com adaptações, a qual possibilitou o trabalho direto no campo e se consistiu em quatro etapas: 1) Entrevistas narrativas com a família; 2) Elaboração de mapas participativos com a família; 3) Caminhadas na unidade de produção indivíduos da família; e 4) Reunião geral com os agricultores representantes das famílias.

Foi preparado um guia para orientar as entrevistas narrativas. Segundo Prudêncio (2011), a entrevista é conduzida a partir de um guia, que é um conjunto de tópicos que "lembram" o pesquisador sobre os objetivos da sua pesquisa, criando um referencial confortável para uma discussão.

As entrevistas narrativas foram realizadas com os familiares que estão ou já estiveram ligados ao trabalho agrícola. As anotações foram registradas em uma caderneta de campo. Na entrevista narrativa, o objetivo é que o entrevistado relate livremente sobre o tema ou assunto abordado. A técnica tenta fugir do esquema pergunta-resposta, para conseguir uma versão menos imposta. A influência do pesquisador é mínima e se reduz a ouvir e manter o informante à vontade para narrar seus conhecimentos (PRUDÊNCIO, 2011).

A elaboração de mapas participativos teve por objetivo facilitar a visualização espacial das classes de terras descritas, e promover a condução das caminhadas pela unidade de produção que proporcionaram a visualização e conhecimento das terras. (GEILFUS, 2002).

Ao finalizar todas as etapas da pesquisa nas unidades de produção, foi realizada uma reunião geral, com oito representantes das famílias de agricultores de Antonina, o qual foi um momento importante para confirmar informações das entrevistas. Em Morretes não foi possível efetivar uma reunião geral devido ao desastre natural ${ }^{7}$ ocorrido em Março de 2011.

\footnotetext{
${ }^{7}$ No dia 11 de Março de 2011, ocorreram chuvas fortes de aproximadamente $230 \mathrm{~mm}$, sendo que a média de para o mês $268,0 \mathrm{~mm}$, ocasionando situação de anormalidade em todo munícipio como alagamentos,
} 
Para averiguar as principais classes de terras e atributos referidos foi realizada a triangulação dos dados, que consistiu em confrontar todas as informações obtidas nas entrevistas, mapas participativos, caminhadas e reunião geral, verificando a frequência de citações e assim construir uma tabela matriz com as classes identificadas (GEILFUS, 2002).

Para a análise da interpretação dos dados foi utilizada a técnica de análise da conversação e da fala. Este é um dos métodos da etnometodologia, que se interessa pela maneira como as pessoas se servem da linguagem para construir um conjunto de ações coordenadas e inteligíveis. Nessa técnica, ocorre análise de materiais orais que podem ser coletados por entrevistas. O pesquisador realiza uma análise detalhada com base na fala dos sujeitos da pesquisa, podendo, assim, identificar categorias utilizadas pelos participantes, como também, seus pontos de vista (BAUER; GASKELL, 2002). Os entrevistados não foram identificados para proteger a privacidade das famílias.

\section{RESULTADOS E DISCUSSÃO}

As principais classes de terras mencionadas pelos agricultores entrevistados apresentaram a seguinte frequência de citação: "Terra de Desmonte" (85\%), "Sabão de Caboclo" (80\%), "Terra Argilosa" (70\%), "Terra de Morro" (60\%). Compreende-se que essa terminologia é compartilhada entre os agricultores locais. Porém, deve ser destacado que a menor porcentagem de citação, em alguns casos, pode estar associada à inexistência dessa classe na unidade de produção rural ou a sua condição de não utilização agrícola (Tabela 1).

Tabela 1 - Tabela matriz das classes etnopedológicas, topografia, atributos, aptidão.

\begin{tabular}{|c|c|c|c|c|}
\hline Classe & Topografia & Principais atributos citados & Aptidão & Uso \\
\hline $\begin{array}{l}\text { "Terra de } \\
\text { Morro" }\end{array}$ & Inclinada & $\begin{array}{l}\text { Cor preta ou vermelha, textura } \\
\text { média: boa drenagem, localizada } \\
\text { nos morros. }\end{array}$ & $\begin{array}{l}\text { Uso agrícola } \\
\text { com } \\
\text { restrições }\end{array}$ & $\begin{array}{l}\text { Culturas } \\
\text { perenes }\end{array}$ \\
\hline $\begin{array}{l}\text { "Sabão de } \\
\text { Caboclo" }\end{array}$ & Plana & $\begin{array}{l}\text { Cor branca, textura argilosa, } \\
\text { consistência extremamente dura } \\
\text { quando seca e extremamente } \\
\text { pegajosa quando molhada, mal } \\
\text { drenada; localiza-se em faixas } \\
\text { distante dos rios. }\end{array}$ & $\begin{array}{l}\text { Inadequada } \\
\text { para uso } \\
\text { agrícola }\end{array}$ & $\begin{array}{l}\text { Reservada } \\
\text { para área } \\
\text { de } \\
\text { preserva- } \\
\text { ção } \\
\text { ambiental }\end{array}$ \\
\hline $\begin{array}{l}\text { "Terra } \\
\text { Argilosa" }\end{array}$ & Plana & $\begin{array}{l}\text { Cor marrom, vermelha, amarela; } \\
\text { textura argilosa: boa drenagem; } \\
\text { localiza-se distante dos rios. }\end{array}$ & $\begin{array}{l}\text { Adequada } \\
\text { para uso } \\
\text { agrícola }\end{array}$ & $\begin{array}{l}\text { Culturas } \\
\text { anuais }\end{array}$ \\
\hline $\begin{array}{l}\text { "Terra de } \\
\text { Desmonte" }\end{array}$ & Plana & $\begin{array}{l}\text { Cor não destacada, textura } \\
\text { arenosa, excelente drenagem, } \\
\text { fertilidade ótima, localizada } \\
\text { próxima aos rios. }\end{array}$ & $\begin{array}{l}\text { Adequada } \\
\text { para uso } \\
\text { agrícola }\end{array}$ & $\begin{array}{l}\text { Culturas } \\
\text { anuais }\end{array}$ \\
\hline
\end{tabular}

Descrições das principais narrativas dos agricultores.

Em relação à espacialização das informações, observou-se que a classificação abrange os agricultores familiares dos dois municípios. Provavelmente,

queda de barreiras, deslizamentos, pontes danificadas/destruídas o que gerou o isolamento de várias localidades, falta de comunicação, falta abastecimento de água, grande número de pessoas desabrigadas e desalojadas, fator esse que dificultou a capacidade exclusiva do município de dar a primeira resposta. Todos esses fatores dificultaram ao retorno da normalidade em curto espaço de tempo (MORRETES, 2011). 
isso se deve à proximidade geográfica dos municípios, pela conjuntura territorial, pois Morretes foi um distrito de Antonina até o ano de 1841 (IPARDES, 2012) e pela história comum do litoral sul/sudeste (MUSSOLINI, 1980).

\subsection{DESCRIÇÕES DAS CLASSES DE TERRA E CRITÉRIOS UTILIZADOS PARA CLASSIFICAÇÃO:}

"Terra de Morro"

Os agricultores entrevistados descreveram a "Terra de Morro" como uma terra encontrada em regiões íngremes, com baixos índices de fertilidade natural e com textura mista (entre areia e argila). Apresenta cores em sua maioria preta, preto-avermelhada e vermelha (Figura 2).

Figura 2 - Áreas de "Terra de Morro" em Morretes (em primeiro plano).

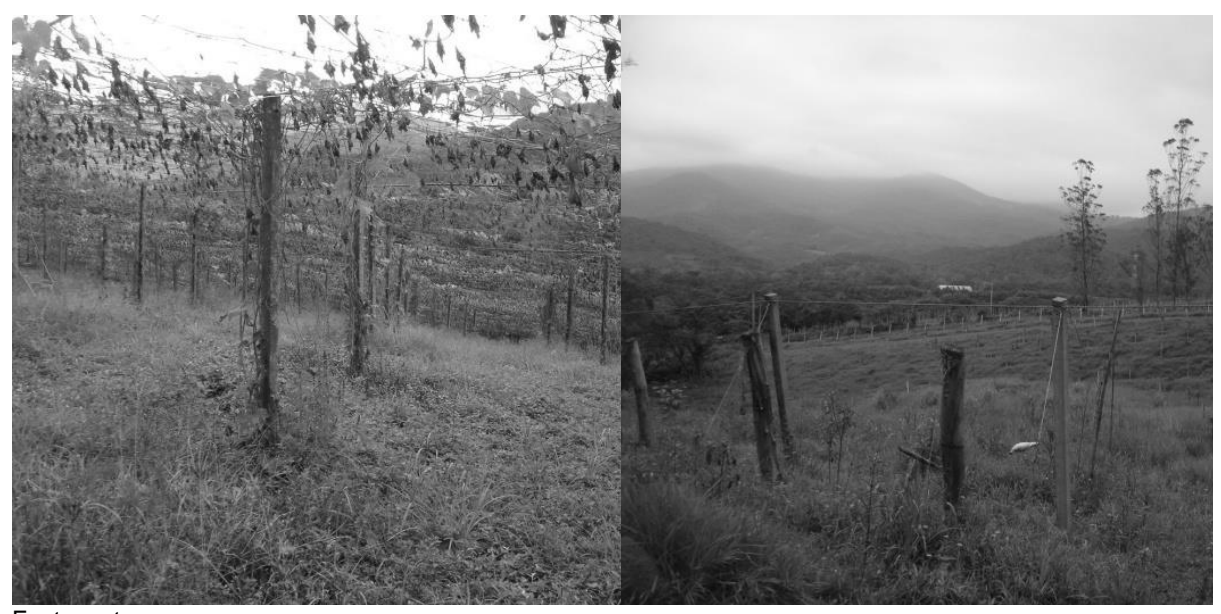

Fonte: autores.

Devido à declividade e à baixa fertilidade natural, esta terra apresenta limitações aos cultivos anuais. Esse aspecto pode ser confirmado através do relato "A gente não planta feijão, milho, essas coisas... porque essa é uma terra fraca e também a água da chuva vem e arranca tudo; é preciso fazer curvas de nível".

Essas áreas são comumente destinadas ao plantio de maracujá, chuchu, palmito, banana ou mandioca, ou seja, cultivos perenes. Segundo os agricultores, essas são culturas que não necessitam de cuidados frequentes e são resistentes à ação da enxurrada. Esses cultivos se encontram inseridos em mata secundária ou nativa e a alternativa utilizada por alguns produtores é mantê-las como áreas de preservação ambiental. Nas unidades de produção estudadas, verificou-se a frequência de cultivos em terras planas, o que foi visualizado durante as caminhadas e confirmado pelo relato de um dos entrevistados "(...) a gente prefere plantar em área plana, aberta e desmatada".

A Terra de Morro foi classificada como uma "terra fraca" no quesito fertilidade verifica-se esta característica no relato do agricultor ao ser questionado de como se identifica a baixa fertilidade da terra: "A gente sabe que a terra é mais fraca 
onde se tem bastante "Jacatirão" e nos morros "tá" cheio". Um dos indicativos da baixa fertilidade da "Terra de Morro", conforme os agricultores, é a presença do "Jaguatirão" ou "Jacatirão", também conhecida popularmente como "Quaresmeira" ou "Manacá da Serra" (Tibouchina mutabilis). De modo semelhante, outras pesquisas etnopedológicas verificaram que plantas são utilizadas pelos agricultores como indicadores da fertilidade do solo (TALAWAR; RHOADES 1998; MAIRURA et al., 2007; et al.,).

\section{"Sabão de Caboclo"}

Os agricultores entrevistados descreveram o "Sabão de Caboclo" como uma terra argilosa, de cor branca, consistência extremamente dura quando seca, lembrando uma "pedra", que retém muita água, muito plástica e muito pegajosa, localizada em faixas longe dos rios (Figura 3).

Figura 3 - Área de "Sabão de Caboclo" em Morretes (esquerda) e aspecto da terra em Antonina (direita).

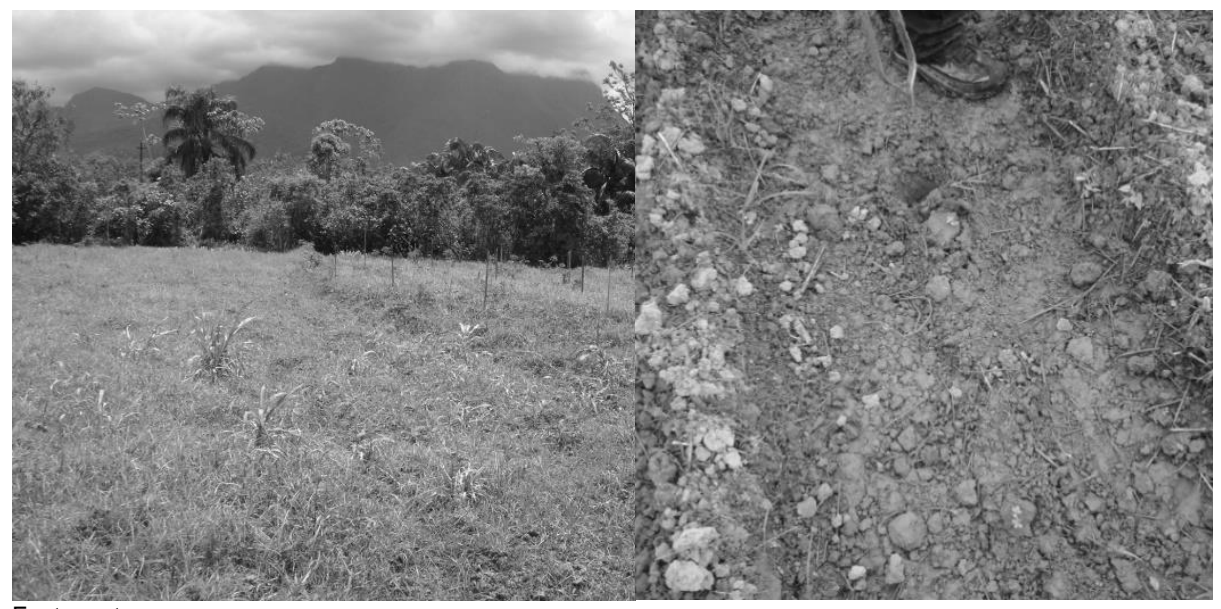

Fonte: autores.

Uma das principais características mencionadas pelos agricultores entrevistados em relação a esta terra foi a dificuldade para a percolação da água, conforme pode ser observado nos relatos: "No Sabão de Caboclo não penetra água". "O Sabão de caboclo demora para enxugar; as plantas chegam a apodrecer". "(...) quando molha, molha muito, segura muita água".

Com relação à consistência, os relatos foram unânimes ao descreverem a extrema dureza do "Sabão de Caboclo" em condições de pouca água: "(...) quando seca vira uma pedra". "(...) é um barro branco duro como um tijolo....".

A cor foi um atributo frequentemente mencionado e a coloração descrita para esta terra é branca, verificada nos relatos: "É uma terra de cor "branquicenta"”. "É uma terra argilosa branca". "(...) é um barro branco duro como um tijolo".

Nesta classe em especial, os agricultores demonstraram perceber variações de cor em função da profundidade. A coloração apresenta modificações 
para tons mais claros ou "esbranquiçados". Conforme o relato "(...) no fundo tem um barro mais branco...". Alguns entrevistados citaram a pegajosidade da terra ao relatar que ela gruda nas ferramentas utilizadas no trabalho agrícola. A textura descrita é "argilosa" e alguns agricultores mais antigos mencionaram o uso do "Sabão de Caboclo" na confecção de peças artesanais, demonstrando que é entendida a elevada plasticidade desta terra.

A localização do "Sabão de Caboclo" em faixas longe dos rios foi verificada através das descrições orais dos agricultores e observada nas caminhadas pelas unidades de produção. Porém alguns dos entrevistados que também são artesãos ceramistas relataram a presença desta terra próxima aos rios.

Em função das características físicas, o "Sabão de Caboclo" foi considerado uma terra marginal para os cultivos comuns da região. Todos os entrevistados concordaram que existem impedimentos às práticas agrícolas. Um dos entrevistados relatou que este solo possui alguma propriedade não identificada por ele que impede o melhoramento. Nesse caso, o agricultor percebe a presença de uma característica intrínseca do solo, como pode ser observado no relato: "O Sabão de Caboclo é uma terra que não se consegue melhorar, você pode adubar, virar, fazer o que for; não adianta".

Esta classe se destacou nas entrevistas por apresentar características particulares e limitantes ao cultivo agrícola. Comumente, essas terras se destinam em áreas de preservação ambiental, porém, em Morretes, verificou-se dois agricultores que cultivam hortaliças no "Sabão de Caboclo". Entretanto, essas são áreas de assentamentos e esses agricultores possuem em sua maioria esta classe presente na sua unidade de produção. A estratégia de manejo do solo utilizada é a adição de elevadas quantidades de matéria orgânica visando melhorar as características físicas, como a consistência do solo e diminuição da pegajosidade, conforme se verifica no relato do agricultor "Se você colocar bastante palha, restos das plantas e esterco isso ajuda a dar uma melhorada nesta terra".

A origem do termo "Sabão de Caboclo" parece ser devida às suas características, como consistência extremamente dura quando seca, por ser pegajosa, reter muita água, ter estrutura maciça e cor branca, que para alguns entrevistados lembra uma "pedra de sabão".

$\mathrm{Na}$ área da construção civil, a terminologia "Sabão de Caboclo" também é utilizada para descrever uma característica particular encontrada em solos de Curitiba - PR e região metropolitana. Em uma pesquisa sobre o comportamento geomecânico da formação Guabirotuba, Kormann (2002), serve-se do termo "Sabão de Caboclo" para se referir às argilas que, em seu estado natural, tornam-se duras e rijas e, quando umedecidas, tornam-se lisas e escorregadias. Segundo a pesquisa, essa terminologia é comumente utilizada entre os trabalhadores da construção civil nessa região.

\section{"Terra argilosa"}

As características descritas pelos agricultores entrevistados em relação à "Terra Argilosa" foram: maior quantidade de argila; cor vermelha, amarela e marrom; boa fertilidade natural; capacidade de reter água em épocas de estiagem; localizada em áreas planas longe dos rios (Figura 4). 
Figura 4 - Áreas de "Terra Argilosa” em Antonina (esquerda) e Morretes (direita).

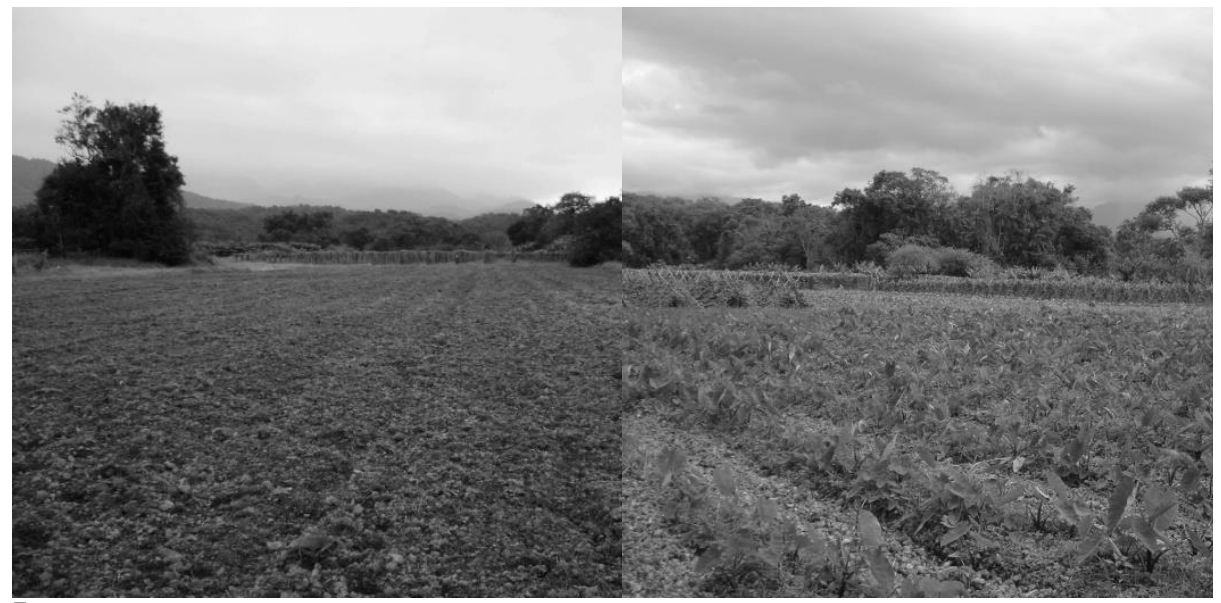

Fonte: autores.

A cor relatada pelos entrevistados foi "avermelhada"; outros mencionaram a cor "marrom" e "amarelada". A textura foi confirmada por diversos relatos como um solo com maior teor de argila ou "barro".

É considerado um solo com boa drenagem, e na ocorrência de período de estiagem o solo armazena água em quantidade satisfatória para a produção agrícola, conforme o relato: "Essa terra não seca quando dá seca". Ao descrever a profundidade, alguns agricultores perceberam a presença de areia no fundo e relataram essa característica da seguinte forma: "É uma terra boa por que em cima tem barro e embaixo tem areia. Isso ajuda na drenagem do solo".

Esta foi a única classe na qual foi relatado o problema de compactação. Isso pode ser devido ao fato de ser uma área de uso agrícola intensivo e por apresentar considerável quantidade de argila, como pode ser verificado no comentário: "(...) compacta com mais facilidade porque tem mais argila".

A fertilidade foi descrita como "uma terra gorda", isto é, apresenta boa fertilidade natural. Entretanto, alguns agricultores entrevistados mencionaram a necessidade de aplicação de fertilizantes e adição de material orgânico para melhorar essa característica.

Frequentemente utilizada na agricultura, a "Terra Argilosa" possui elevada aptidão agrícola para lavouras anuais, e na região se costuma destiná-las à produção de olerícolas ou cultivos denominados "culturas de raízes", que são tubérculos e raízes tuberosas comuns na região, como o gengibre (Zingiber officinale), inhame (Colocásia sp.), mandioca (Manihot sp.).

\section{"Terra de Desmonte"}

Segundo os agricultores entrevistados, a "Terra de Desmonte" é "arenosa" e apresenta excelente aptidão agrícola. Está localizada na beira dos rios e sofre influência das águas em períodos de cheia, quando ocorre o enriquecimento da fertilidade desta terra (Figura 5). 
Figura 5 - Área de "Terra de Desmonte" em Antonina (esquerda) e Morretes (direita).

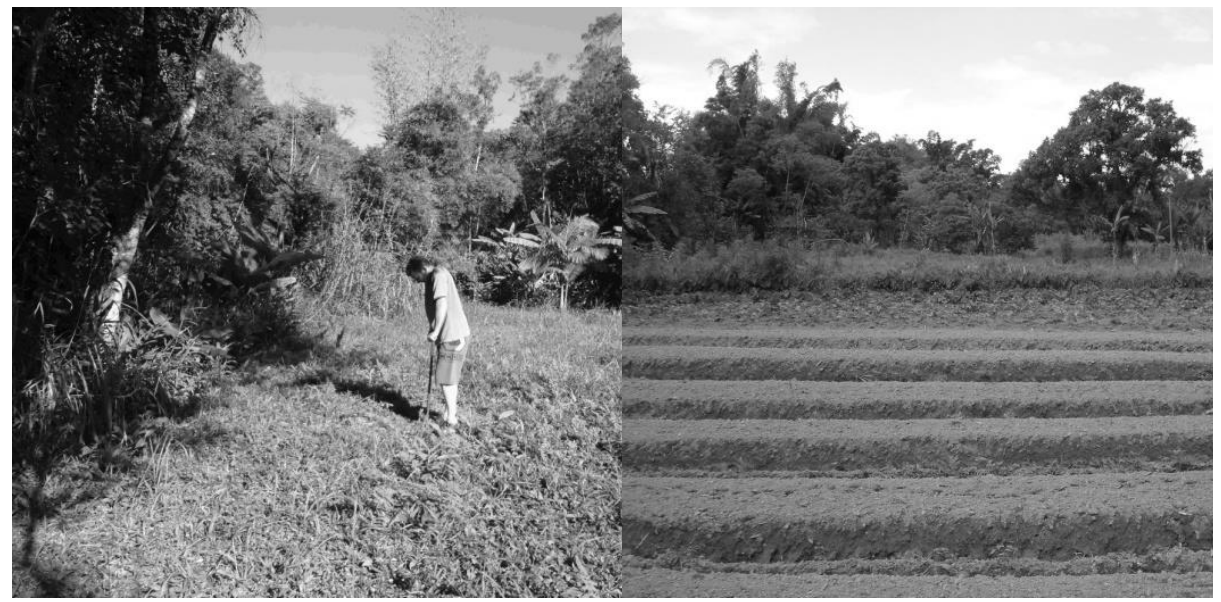

Fonte: autores.

Segundo os agricultores entrevistados, a "Terra de Desmonte" é "arenosa" e apresenta excelente aptidão agrícola. Está localizada na beira dos rios e sofre influência das águas em períodos de cheia, quando ocorre o enriquecimento da fertilidade desta terra (Figura 5).

Por apresentar as melhores características para a agricultura, os entrevistados a descreveram como tendo ótima fertilidade e que essa característica está relacionada com a proximidade do rio. É percebido pelos agricultores que a fertilidade é oriunda das águas dos rios quando ocorrem enchentes, conforme a descrição: "Quando alaga, a água suja ajuda a melhorar a terra". Foi comentada a presença de matéria orgânica em boa quantidade, e essa característica também estaria relacionada à boa fertilidade.

Resultado semelhante foi encontrado por Pereira et al. (2006), em um estudo etnopedológico com agricultores do planalto sul catarinense, no qual os agricultores relacionam a fertilidade com a localização das glebas e as que apresentam melhores características estão localizadas às margens dos rios e baixadas.

A textura é considerada "arenosa", sendo um atributo muito valorizado, relacionado à boa drenagem do solo e importante para o cultivo de raízes tuberosas, conforme os relatos: "Nessa terra arenosa é melhor para produzir; quando chove muito não "empoça" água". "(...) "alaga quando o rio sobe, mas logo, logo a água vai embora, a terra "chupa" a água bem rápido".

Resultado similar foi encontrado por Briggs et al. (1998), em uma pesquisa com agricultores egípcios, na qual os melhores solos foram considerados os que possuíam uma textura argilo-arenosa, sendo que o teor de areia foi relacionada à boa drenagem, característica importante para solos próximos a rios e que podem sofrer inundação.

Talawar; Rhoades (1998), realizaram uma análise comparativa de como agricultores e cientistas classificam e utilizam os solos, e verificaram a importância da textura em diversas pesquisas etnopedológicas. Segundo esses autores, esse 
atributo desempenha um papel crucial, pois a partir dele é que são tomadas decisões relacionadas aos cultivos e manejo. Os agricultores entrevistados por esses autores relataram que esses solos são considerados leves e fáceis de cultivar e permitem a infiltração de água. Esses aspectos também foram mencionados pelos agricultores entrevistados em Antonina e Morretes.

Houve poucos relatos relacionados à coloração da terra, entretanto, as terras de cores mais escuras são consideradas de melhor qualidade no quesito fertilidade, conforme as descrições dos entrevistados, que enfatizaram a vocação agrícola que esta terra apresenta.

A terminologia utilizada tem procedência nas observações cotidianas dos agricultores, pois eles relatam que a nomenclatura "terra de desmonte" é devida às enchentes das águas dos rios que, em períodos chuvosos, provocam o "desmonte do barranco do rio", ou seja, desmoronamento das margens e, em seguida, esses sedimentos são depositados em áreas a jusante no curso do rio, causando, então, a melhoria da fertilidade do solo.

O termo "Terra de Desmonte" também foi relatado por Koch et al.(2002), em um trabalho linguístico e etnográfico da Região Sul do Brasil, para designar margens de rios ou áreas que permanecem cobertas por água por determinado tempo.

\subsection{ATRIBUTOS DIAGNÓSTICOS EMPREGADOS NAS CLASSES ETNOPEDOLÓGICA}

A classificação local de terras é baseada em informações qualitativas, sendo que os principais atributos morfológicos mencionados pelos agricultores entrevistados e suas respectivas frequências de citação foram: 1) posição na paisagem (combinação de relevo e localização) (100\%); 2) textura (94\%); 3) cor $(79 \%)$; 4) drenagem (67\%); 5) fertilidade (64\%); 6) consistência (42\%); e 7) matéria orgânica (23\%). Cada terra identificada possui atributos determinantes para sua classificação (Tabela 2).

Tabela 2 - Atributos diagnósticos utilizados para classificação etnopedológica

\begin{tabular}{ll}
\hline \multicolumn{1}{c}{ Classe etnopedológica } & \multicolumn{1}{c}{ Principais atributos } \\
\hline "Terra de Morro" & Posição na paisagem, textura, cor, fertilidade. \\
"Sabão de Caboclo" & Posição da paisagem, textura, cor, drenagem, consistência. \\
"Terra Argilosa" & $\begin{array}{l}\text { Posição da paisagem, textura, cor, fertilidade, drenagem. } \\
\text { "Terra de Desmonte" }\end{array}$ \\
$\begin{array}{l}\text { Posição na paisagem, textura, fertilidade, matéria orgânica, } \\
\text { influência do rio. }\end{array}$ \\
\hline
\end{tabular}

Resultados similares foram encontrados por Toledo; Barrera-Bassols (2008), em uma revisão de literatura sobre os critérios utilizados por camponeses e indígenas nas classificações etnopedológicas do mundo. Nas pesquisas, comumente são citados os atributos: cor (100\%); textura (98\%); consistência (56\%); umidade do solo (55\%); e matéria orgânica, pedregosidade, topografia, uso da terra e drenagem com menor importância.

A posição na paisagem (Figura 6) foi um atributo citado em todas as classes de solos reconhecidas pelos agricultores, verificou-se que esta é determinante para a classificação etnopedológica nesta pesquisa. De modo semelhante, Siderius e Bakker (2003) verificaram que agricultores holandeses 
também utilizam estes atributos, posição na paisagem e textura, para classificação e para a tomada de decisões relacionadas ao uso e manejo do solo.

Figura 6 - Diagrama da posição na paisagem da classificação etnopedológica: 1 "Terra de Morro", 2 - "Sabão de Caboclo", 3- "Terra Argilosa", 4 - "Terra de Desmonte".

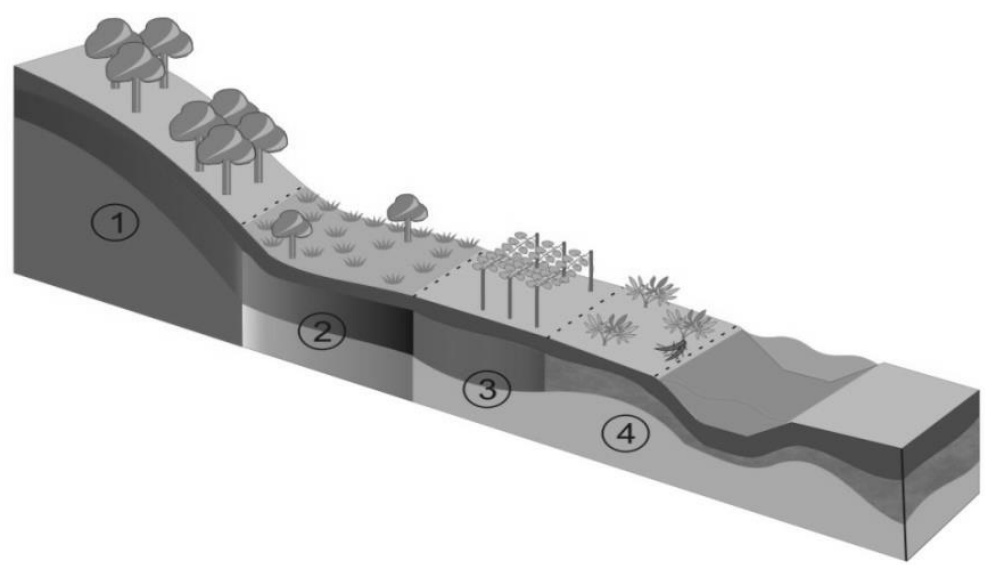

Fonte: autores.

A textura e a cor também foram atributos do solo frequentemente mencionados pelos agricultores entrevistados por Queiroz; Norton (1992), no Vale do rio Acaraú (CE); Briggs et al. (1998), no Egito; Ryder (2003), na República Dominicana; Talawar; Rhoades (1998), em um estudo bibliográfico; e Vale Júnior et al. (2007), com indígenas em Roraima.

Em relação à cor, as terras que apresentaram cores escuras foram consideradas férteis pelos agricultores entrevistados em Morretes e Antonina, de modo semelhante aos resultados encontrados por Mairura et al. (2007), em uma pesquisa com agricultores de dois vilarejos no Quênia, bem como por Ryder (2003), com agricultores dominicanos, e Pereira et al. (2006), no planalto sul catarinense.

A textura é a quantidade de argila ou areia presente no solo, para os entrevistados, ela desempenha uma função primordial, pois se determina a forma de uso e manejo do solo. Resultados semelhantes foram encontrados por Osunade (1988), com agricultores nigerianos e por Talawar; Rhoades (1988), em uma revisão bibliográfica sobre o tema.

Para constatar a fertilidade os agricultores utilizam uma combinação de variáveis, observam o desenvolvimento das plantas, a cor escura do solo, a quantidade de matéria orgânica, textura e outros. Resultados semelhantes foram encontrados em diversos trabalhos (BRIGGS et al., 1998; MAIRURA et al., 2007; SIDERIUS; BACKER, 2003; et al.,).

A consistência do solo foi frequentemente mencionada quando os entrevistados descreviam a terra "Sabão de Caboclo" isto provavelmente se deve pela característica diferenciada desta terra em relação ás outras. 


\section{CONCLUSÕES}

O sistema de classificação dos agricultores de Antonina e Morretes, litoral do estado do Paraná, possibilitam a identificação e descrição das terras agrícolas utilizando atributos do solo e os relacionando com aspectos cognoscíveis como aptidão agrícola e manejo do solo. Foram identificadas e descritas quatro classes de terras: "Terra de Morro", "Sabão de Caboclo", "Terra Argilosa" e "Terra de Desmonte". A identificação dessas classes é fundamentada em atributos diagnósticos, sendo empregados na seguinte frequência: 1) posição na paisagem (combinação de relevo e localização); 2) textura; 3) cor; 4) drenagem; 5) fertilidade; 6) consistência; e 7) matéria orgânica. Cada classe de terra identificada possui atributos determinantes para sua classificação.

\section{AGRADECIMENTOS}

Agradeçemos a todos os agricultores e agricultoras que dedicaram seu tempo e atenção para a realização desta pesquisa.

\section{REFERÊNCIAS}

ALVES, A. G. C.; MARQUES, J. G. W. Etnopedologia: uma nova disciplina? In: VIDAL-TORRADO, P. Tópicos em ciência do solo IV. Viçosa, Sociedade Brasileira de Ciência do Solo, 2005.

BARRERA-BASSOLS, N.; ZINCK J. A. Ethnopedology in a worldwide perspective. Enschede: International Institute for Aerospace and Earth Sciences, 2000.

BARRIOS, E.; DELVE, R. J.; BEKUNDA, M.; MOWO, J.; AGUNDA, J.; RAMISCH, J.; TREJO, T. M.; TOMAS, R. J. Indicators of soil quality: a South-South development of a methodological guide for linking local and technical knowledge. Geoderma, v. 135 p. 248-259, 2006.

BAUER, M. W.; GASKELL, G. Pesquisa qualitativa com texto, imagem e som: um manual prático. Petrópolis: Vozes, 2002.

BENASSI, D. A.; SANTOS, J. A. B.; GIAROLA, N. F. B. Conhecimentos etnopedológicos dos agricultores do centro-sul do Paraná. Revista Brasileira de Agroecologia, v. 4, n. 2, p. 1862-1865, 2009.

BHERING, S. B.; SANTOS, H. G. (Eds.). Mapa de solos do estado do Paraná: legenda atualizada. Rio de Janeiro: Embrapa Solos, 2008.

BIRMINGHAM, D. M. Local knowledge of soils: the case of contrast in Côte d'Ivoire. Geoderma, v. 111, p. 481-502, 2003.

BLAIKIE, N. W. H. Designing social research: The logic of anticipation. London: Polity Press, 2002. 
BOULAINE, J. Histoire des pedologues et de la science des sols. Paris: Institute National de la Recherce Agronomique, 1989.

BRIGGS, J.;PULFORD, I. D.; BADRI, M.; SHAHEEN, A. S. Indigenous and scientific knowledge: the choice and management of cultivation sites by bedouin in Upper Egypt. Soil Use and Management, v. 14, n. 4, p. 240-245, 1998.

CORREIA, J. B.; ANJOS, L. H.; LIMA, A. C. S.; NEVES, D. P.; TOLEDO, L. O.; CALDERANO, F.; SHINZATO, E. Relação entre o conhecimento de agricultores e de pedólogos: estudo de caso em Rio Pardo de Minas, MG. Revista Brasileira de Ciência do Solo, v. 31, n. 5, p. 86-92, 2007.

CURI, N.; LARACH, J. O. I.; KÄMPF, N.; MONIZ, A. C.; FONTES, L. E. F. Vocabulário de ciência do solo. Campinas: Sociedade Brasileira de Ciência do Solo, 1993.

DAWOE, E. K.; QUASHIE-SAM J.; ISAAC, M. E.; OPPONG S. K. Exploring farmers' local knowledge and perceptions of soil fertility and management in the Ashanti Region of Ghana. Geoderma, v. 179, p. 96-103, 2012.

GEILFUS, F. 80 herramientas para el desarrollo participativo: diagnóstico, planificación, monitoreo, evaluación. San José: Instituto Interamericano de Cooperación para la Agricultura, 2002.

HABARUREMA, E.; STEINER, K. G. Soil suitability classification by farmers in southern Rwanda. Geoderma, v. 75, p. 75-87, 1997.

IBGE, Instituto Brasileiro de Geografia e Estatística. Manual técnico da vegetação brasileira. Disponível em: biblioteca.ibge.gov.br/visualização/livros/liv63011.pdf. Acesso em: 25 jul. 2012.

IPARDES, INSTITUTO PARANAENSE DE DESENVOLVIMENTO ECONÔMICO E SOCIAL. Cadernos estatísticos dos municípios. Disponível em: www.ipardes.gov.br/MontaCadPdf1.php?Municipio=83350. Acesso em 14 abr. 2012.

$\mathrm{KOCH}, \quad$ W.; KLASSMANN, M. S.; ALTENHOFEN, C. V. Atlas linguísticoetnográfico da Região Sul do Brasil, Porto Alegre/Florianópolis/Curitiba: UFRGS/UFSC/UFPR, 2002.

KORMANN, A. C. M. Comportamento Geomecânico da formação Guabirotuba estudos de campo e laboratório. 2002. 429 f. Tese (Doutorado em Engenharia de Solos) - Universidade de São Paulo, São Paulo.

KRASILNIKOV, P. V.; TABOR, J. A. Perspectives on utilitarian ethnopedology. Geoderma, v. 111, p. 19-26, 2003.

MAIRURA, F. S.; MUGENDI, D. N.; MWANJE, J. I.; RAMISCH, J. J; MBUGUA, P. K.; CHIANU, J. N. Integrating scientific and farmers evaluation of soil quality indicators in Central Kenya. Geoderma, v. 139, n. 1, p. 134-143, 2007.

MAZOYER, M.; ROUDART, L. História das agriculturas no mundo: do neolítico à crise contemporânea. São Paulo: Unesp, 2010. 
MORRETES. Decreto $n^{\circ}$ 11/2011, de 12/03/2011. Declara em situação anormal, Caracterizada como estado de calamidade pública a área o município afetada por Enxurradas ou Inundações Bruscas. Disponível em: https://goo.gl/FFAoPM. Acesso em 05 fev. 2013. Acessado em 05/02/2013.

MUSSOLINI, G. Ensaios de antropologia indígena e caiçara. Rio de Janeiro: Paz e Terra, 1980.

OSUNADE, M. A. A. Soil Suitability Classification by Small Farmers. The Professional Geographer, v. 40, n. 2, p. 194-201, 1988.

OUDWATER, N.; MARTIN, A. Methods and issues in exploring local knowledge of soils. Geoderma, v. 111, n. 3, p. 387-401, 2003.

PALACIO V. E. A.; ARRIAGA C. M. O. Classificación campesina de suelos una metodología para para el desarrollo sustentable en el agro. Revista Ideas Ambientales, v. 2, n. 2, p. 199-207, 2005.

PEREIRA, J. A.; FERT NETO, J.; CIPRANDI, O.; DIAS, C. E. A. Conhecimento local, modernização e o uso e manejo do solo: um estudo de etnopedologia no planalto sul catarinense. Revista de Ciências Agroveterinárias, Lages, v. 5, n. 2, p. 140-148, 2006.

PRUDÊNCIO, K. Metodologia de pesquisa. Curitiba: UFPR, 2011.

QUEIROZ, J. S.; NORTON, B. E. An assessment of an indigenous soil classification used in the caatinga region of Ceará State, Northeast Brazil. Agricultural Systems, v. 39, n. 3, p. 289-305, 1992.

RYDER, R. Local soil knowledge and site suitability evaluation in the Dominican Republic. Geoderma, v. 111, n. 3, p. 289-305, 2003.

SAITO, K.; LINQUIST, B.; KEOBUALAPHA, B.; et al. Farmers' knowledge of soils in relation to cropping practices: A case study of farmers in upland rice based slashand-burn systems of northern Laos. Geoderma, v. 136, p. 64-74, 2006.

SIDERIUS, W.; BAKKER, H. Toponymy and soil nomenclature in the Netherlands. Geoderma, v. 111, n. 3, p. 521-536, 2003.

SILLITOE, P. Knowing the land: soil and land resource evaluation and indigenous knowledge. Soil Use and Management, v. 14, n. 4, p. 188-193, 1998.

SOUZA FILHO, E. T. Microbacia hidrográfica do Riacho Vazante, Aratuba, Ceará: solos uso e percepção de agricultores. 2006. 55 f. Dissertação (Mestrado em Solos e Nutrição de Plantas) - Programa de Pós-Graduação em Solos e Nutrição de Plantas, Universidade Federal de Viçosa. 
STRACHULSKI, J.; FLORIANI, N. Formação do sistema agrário na região do Paraná tradicional: Um estudo de caso da comunidade rural Linha Criciumal em Candido de Abreu. Extensão Rural, Santa Maria, v. 21, n. 3, p. 146-174, 2014.

TALAWAR, S.; RHOADES R. E. Scientific and local classification and management of soils. Agriculture and Human Values, v. 15, n. 1, p. 3-14, 1998.

TOLEDO, V. M.; BARRERA-BASSOLS N. La memória biocultural, la importância ecológica das sabidurías tradicionales. Barcelona: Icaria, 2008.

VALE JUNIOR, J. F.; SCHAEFER, C. E. G. R.; COSTA, J. A. V. Etnopedologia e transferência de conhecimento: diálogos entre os saberes indígenas e técnicos na Terra Indígenas Malacacheta, Roraima. Revista Brasileira de Ciência do Solo, v. 31, n. 2, p. 403-412, 2007.

WILLIAMS, B. J. Aztec soil science. In: WARKETIN, P. B. Footprints in the soil people and ideas in soil history. Amsterdan: Elsevier, 2006.

WINIWARTER, V. Soil scientistis is ancienti Rome. In: WARKETIN, P.B. Footprints in the soil people and ideas in soil history. Amsterdan: Elsevier, 2006. 